\title{
TRABALHO EM SAÚDE MENTAL: VIVÊNCIAS DOS PROFISSIONAIS DIANTE DOS RESULTADOS ${ }^{1}$
}

\author{
Vinicius Carvalho de Vasconcellos* \\ Creuza Azevedo ${ }^{\#}$
}

\begin{abstract}
RESUMO. Considerando o cenário de consolidação da reforma psiquiátrica brasileira, este artigo investigou, no contexto dos trabalhadores da saúde mental, representações relativas ao papel profissional, às vivências diante dos resultados da assistência e às expectativas do futuro profissional da Saúde, tratando igualmente da possível ligação entre esses elementos. O material empírico foi coletado por meio de oito entrevistas semiestruturadas, realizadas em um Centro de Atenção Psicossocial brasileiro, e analisado principalmente pelo referencial teórico da psicossociologia francesa. De modo geral, os resultados sugerem que a vivência de realização diante dos resultados do trabalho vinculase ao cumprimento do papel profissional, indicando também a ligação entre esses últimos elementos e as expectativas do futuro profissional. Na discussão e nas considerações finais, ressalta-se a concepção do trabalho por meio de seus limites intrínsecos como mecanismo que atenua a frustração profissional e analisam-se as implicações das vivências relativas aos resultados no vínculo subjetivo dos profissionais com o trabalho.
\end{abstract}

Palavras-chave: Saúde mental; trabalho; reforma psiquiátrica.

\section{MENTAL HEALTH WORK: PROFESSIONAL'S EXPERIENCES FACING THE OUTCOMES}

\begin{abstract}
Considering the scenario of consolidation of Brazilian psychiatric reform, this paper investigated in the context of mental health workers, representations relating to the professional role, experiences before the results of assistance and the expectations of future career, addressing also the possible link between these elements. and analyzed mainly through the theoretical framework of the French Social Psychology. Overall, the results suggest that the experience of holding forth the results of the study is linked to the performance of the professional role, also indicating the connection between these latter elements and the career's expectations. In the discussion and conclusion, it emphasizes the conception of the work through its intrinsic limitations as a mechanism that mitigates the professional frustration and it also analyzes the implications of experiences concerning the results of subjective professional relationship with the work.
\end{abstract}

Key words: Mental health; labour; psychiatric reform.

\section{TRABAJO EN SALUD MENTAL: VIVENCIAS DE PROFISIONALES DELANTE LOS RESULTADOS}

RESUMEN. Ante la consolidación de la reforma psiquiátrica brasileña, este trabajo investigó, en el contexto de los trabajadores de la salud mental, las representaciones sobre el papel profesional, las vivencias delante los resultados del cuidado y las expectativas de futuro profesional, abordando también la posible relación entre estos elementos. El material empírico fue recogido a través de ocho entrevistas semiestructuradas llevadas a cabo en un Centro de Atención Psicosocial brasileño y analizado a partir del referencial teórico de la psicossociología francesa. Este análisis mostró que la realización/frustación asociada con los resultados del trabajo está conectada con el cumplimiento del papel profesional y con las expectativas de futuro profesional. La discusión y las observaciones finales acentúan la concepción del trabajo a través de sus limitaciones intrínsecas como mecanismo que mitiga la frustración profesional y analiza las implicaciones de las vivencias de los profesionales en su relación con el trabajo.

Palabras-clave: Salud mental; trabajo; reforma psiquiátrica.

\footnotetext{
1 Apoio e Financiamento: CNPq

Mestre em Saúde Pública pela Fundação Oswaldo Cruz. Doutorando do Programa de Psicologia Social, do Trabalho e das Organizações da Universidade de Brasília, Brasil.

\# Doutora em Psicologia pela Universidade de São Paulo. Professora e pesquisadora da Fundação Oswaldo Cruz, Brasil.
} 
Ao longo das últimas décadas o modelo assistencial de saúde mental no Brasil sofreu perceptível alteração a partir da reforma psiquiátrica e da busca pela superação do modelo manicomial. Nesta linha, a política oficial da área advoga, dentro da perspectiva de atenção psicossocial, a promoção da cidadania entre os usuários dos serviços, sua inserção social, o estabelecimento de projetos terapêuticos individualizados e a interdisciplinaridade no cuidado (Brasil, 2004). A partir dessa perspectiva, desenvolvese uma rede assistencial que valoriza dispositivos extra-hospitalares como os Centros de Atenção Psicossocial (CAPSs), a Estratégia da Saúde da Família e a Atenção Básica, além das residências terapêuticas (Brasil, 2004).

Esse cenário, além de modificar as políticas públicas, pode repercutir de diversas maneiras na atuação dos profissionais e na sua relação com o trabalho, questões que, com efeito, instigaram investigações acadêmicas. Por exemplo, diversas pesquisas, de modo direto ou indireto, ao analisarem a atuação profissional à luz das proposições da reforma psiquiátrica, encontraram resultados divergentes. Assim, alguns estudos ressaltam inserções profissionais assaz encerradas no espírito da reforma, denotando um cuidado alicerçado na reflexão e na mudança social (Honorato \& Pinheiro, 2008; Nunes, Torrenté, Ottoni, Moraes Neto \& Santana, 2008), enquanto outros destacam profissionais mergulhados, ao mesmo tempo, na psiquiatria tradicional e na possibilidade de reforma, explicitando a subsistência de códigos de conduta típicos das práticas manicomiais (Garcia \& Jorge 2006; Koda \& Fernandes, 2007).

Adicionam-se a estas pesquisas outras investigações que indicam o esvaziamento da dimensão política e social da reforma psiquiátrica e da proposta de desinstitucionalização, estando estes processos reduzidos à dimensão técnico-assistencial e ao modelo clínico tradicional (Bueno \& Caponi, 2009; Figueiredo \& Rodrigues, 2004). De modo similar, Pinto e Ferreira (2010), em artigo teórico, questionam as práticas inseridas no paradigma da reabilitação psicossocial e ponderam sobre os riscos de manutenção dos assistidos na condição de psiquiatrizados. Tomadas em conjunto, as pesquisas parecem indicar que a atuação profissional encontra-se em processo de transição, no qual as diretrizes da política pública e o imaginário da reforma, apesar de salientes, ainda esgrimam para se estabelecer plenamente.

Não obstante, mesmo em um cenário de transição, a saúde mental depara-se com a necessidade de resolutividade e efetividade em suas práticas. Isto significa que a expectativa de bons resultados, seja por parte da sociedade, dos assistidos ou dos profissionais, faz parte da relação de cuidado, não importando o estágio de maturação do processo. No fundo, a implantação do novo modelo assistencial pode aguçar ainda mais a demanda por resultados positivos, pois tais resultados trariam relevante impulso no sentido de sobrepujar qualquer resquício do modelo manicomial. Essa demanda por resultados positivos, contudo, deve lidar com os objetivos complexos e ambiciosos propostos pelas políticas públicas e, concomitantemente, com as frágeis condições de trabalho no Sistema Único de Saúde (SUS), incluindo baixos salários, insuficiente carga de treinamento, reduzida perspectiva profissional, falta de material e instalações precárias.

Em um contexto que conjuga grandes desafios e dificuldades para sua obtenção, cabe interrogar sobre as possíveis vivências dos profissionais diante dos resultados do seu trabalho, especialmente suas experiências e reações afetivas.

No que concerne à relação afetiva dos profissionais de saúde mental com seu o trabalho, cumpre destacar o estudo de Rebouças, Legay e Abelha (2007), embora esta investigação esteja centrada na satisfação com o trabalho, construto que não embasa a presente pesquisa. As autoras encontraram profissionais com nível intermediário de satisfação, estando mais satisfeitos aqueles com mais idade e os que participavam de projetos assistenciais ligados à reforma psiquiátrica. No caso da idade, a pesquisa indica que, provavelmente, indivíduos mais velhos tendem a ser mais experientes e maduros no trabalho, podendo, assim, elaborar estratégias adaptativas diante das adversidades.

Ao discutir as experiências/reações afetivas relacionadas aos resultados do trabalho, convém indagar, igualmente, como os trabalhadores concebem seu papel profissional, iniciativa que permite compreender melhor o contexto no qual emergem tais experiências/reações, especialmente considerando-se a variabilidade das práticas em saúde mental. Essa variabilidade - cabe frisar - não versa apenas sobre o alinhamento ou não às propostas da reforma, mas toca também na coexistência de diferentes linhas teóricopráticas dentro da própria reforma psiquiátrica, que não pode ser assumida como um movimento único e coeso (Bezerra Júnior, 1999). Em meio à reconstrução do campo, tal diversidade de referências está acompanhada, como refere recente revisão de literatura, de certa imprecisão por parte dos profissionais no tocante à concepção de doença mental, que comumente emerge pautada por significados variados e por alusões às suas causas e consequências, preterindo-se assim definições 
teoricamente estruturadas (Prebianchi \& Falleiros, 2011).

Distante de um acordo conceitual entrecortado por múltiplas referências e apartado da consagração de protocolos de atendimento, o papel do profissional em saúde mental adquire certa peculiaridade na saúde pública. Como ilustração, a busca pela cura, tão presente em outras áreas da saúde, reveste-se de especificidade na saúde mental, tanto por ser conceitual e operacionalmente menos tangível, quanto por estar vinculada a uma concepção biomédica de loucura criticada na reforma psiquiátrica. Assim, partindo das características da assistência em saúde mental citadas, torna-se relevante conhecer a visão dos trabalhadores sobre seu papel profissional e a possível associação entre o cumprimento/não cumprimento dos distintos elementos desse papel e determinadas vivências diante dos resultados do trabalho.

Outra questão que merece atenção diz respeito a eventuais repercussões dessas vivências no modo como os participantes da pesquisa vislumbram seu futuro profissional. No contexto estadunidense, Blankertz e Robinson (1997) sublinham a exaustão emocional e o baixo nível de realização profissional, entre outras variáveis, como preditoras de intenção de desligamento dos serviços de saúde mental. Mesmo partindo de referenciais teóricos e métodos distintos daqueles adotados aqui, esses resultados sugerem a ligação entre as experiências afetivas dos trabalhadores e as expectativas de um futuro profissional da saúde mental, sendo importante investigar tal possibilidade na realidade brasileira.

As questões assinaladas acima constituem o cerne da presente pesquisa e serão analisadas à luz da psicossociologia francesa, dada sua ênfase nas relações afetivas, simbólicas e imaginárias dos indivíduos com as organizações e o trabalho. Calçada na teoria psicanalítica, na sociologia e na filosofia, esse referencial teórico assume o fenômeno organizacional em sua dimensão intersubjetiva e balizou pesquisas recentes no contexto da saúde pública brasileira, oferecendo contribuições originais para o estudo do trabalho na área (Azevedo, Fernandes \& Carreteiro, 2007; Sá, 2009; Sá, Carreteiro \& Fernandes, 2008). Nesta abordagem o olhar clínico se faz presente, valorizando assim a singularidade de cada situação e a construção dos sentidos do trabalho (Lévy, 2001).

Em conformidade com o exposto, assume-se a premissa de que a vida nas organizações não se restringe ao trabalho executado, mas essas se afiguram como lugares transpassados pelo desejo, onde convivem o prazer da conquista e a angústia do fracasso (Freitas, 2000). Estas manifestações estão vinculadas irremediavelmente a um trabalho representacional, de pensamento e imaginação dos sujeitos nos quais estes procuram permanentemente explicações e significações para a experiência vivida na organização (Araújo, 2002; Lévy, 2001). Nesta linha, os trabalhadores constroem representações sobre seu próprio papel profissional, um dos focos de análise dessa pesquisa.

A psicossociologia francesa expõe a luta pelo reconhecimento desta questão como nevrálgica no elo entre o indivíduo e a organização (Enriquez, 1997), que se traduz na capacidade da organização e do trabalho de responder aos desejos de afirmação narcísica dos seus empregados. Enriquez (1994) destaca que, em formações grupais e sociais, os sujeitos orientam-se pelo reconhecimento dos seus desejos, o que se relaciona com vivências e afetos vinculados ao andamento do seu próprio trabalho. Delimita-se assim a organização como um ambiente no qual os indivíduos lutam por sua afirmação narcísica em um constante esforço de significação/representação de suas experiências de sucesso/realização e de fracasso/frustração diante dos resultados do trabalho.

Por seu turno, a noção de contrato narcísico, resgatada por Kaës (1997), defende que cada sujeito é portador de um lugar no conjunto social, um lugar que é reconhecido e reforçado pelos membros do grupo. $\mathrm{O}$ lugar social dos profissionais de saúde mental está investido da presunção de uma capacidade de intervenção positiva no sofrimento psíquico alheio, papel que é sustentado na cena assistencial pelos usuários dos serviços, pelos seus familiares e pela sociedade em geral. Se esse mandato social pode alimentar, no extremo, uma autoimagem de potência, em função da suposição de saber e do poder exercido pelos profissionais, isto não esconde a possibilidade de ele gerar, inversamente, frustração profissional em uma situação de malogro. De toda forma, o reforço desse lugar social parece depender da percepção de avanços ou resultados positivos nas práticas assistenciais, ponto relevante para a análise aqui empreendida.

A partir do referencial da psicossociologia francesa e dos pontos levantados acima, este artigo, aprofundamento de um trabalho anterior (Vasconcellos, 2010), apresentou como objetivo geral investigar as vivências dos trabalhadores diante dos resultados assistenciais, buscando conhecer como esses resultados surgem nos seus discursos e quais são as experiências/reações afetivas associadas. Resultados assistenciais são entendidos aqui como os efeitos ou o desfecho de determinada atuação do profissional, enxergados sob a ótica do trabalhador. 
Em complemento, esta pesquisa visou a deslindar a articulação dessas vivências com as representações de papel profissional, assim como sua possível repercussão nas expectativas de futuro profissional, sempre considerando o ponto de vista do trabalhador.

\section{MÉTODO}

\section{Participantes}

O universo de investigação foi um CAPS II da cidade do Rio de Janeiro que atende normalmente entre 20 e 35 usuários/dia, mormente psicóticos e neuróticos graves. A seleção dos profissionais para participar da pesquisa observou dois critérios: (a) estar envolvido diretamente nas práticas assistenciais, excluindo-se, assim, funcionários de apoio, como aqueles responsáveis pela limpeza e pela alimentação; e (b) trabalhar há pelo menos um ano no CAPS, tempo que fornece maior capacidade reflexiva e narrativa sobre a experiência de trabalhar nesse serviço. Se o profissional atendesse a esses parâmetros, existia um único critério de exclusão, a saber, sua recusa ao convite para ser entrevistado.

No curso da pesquisa, foram entrevistados oito profissionais de um total de onze elegíveis pelos critérios estabelecidos. A amostra incluiu várias profissões (psiquiatra, psicólogo, terapeuta ocupacional, musicoterapeuta e auxiliar de enfermagem), contou com cinco mulheres e três homens e, quanto à idade, abrangeu profissionais jovens e veteranos. O tempo médio de serviço foi de 3,5 anos. Nas últimas entrevistas, notou-se a saturação dos temas investigados, o que avalizou o uso do critério de saturação ou exaustão de Bertaux (1997).

\section{INSTRUMENTOS}

Os dados utilizados neste artigo foram coletados por meio de entrevistas semiestruturadas, conquanto a pesquisa original tenha contado com cerca de vinte sessões de observação participante. O roteiro das entrevistas incluiu questões sobre como os profissionais enxergavam seu papel na assistência e os objetivos do trabalho, as quais instigaram relatos sobre as práticas assistenciais e a relação profissionalusuário. $\mathrm{O}$ roteiro abarcou também indagações sobre as vivências relativas aos resultados do trabalho (com ênfase nas frustrações, realizações e reações afetivas em geral), abordando similarmente como entrevistados imaginavam seu futuro profissional e quais eram suas expectativas de inserção profissional no horizonte de cinco anos, incluindo sua intenção de continuar ou não em serviços como os CAPSs.

\section{Procedimento}

As entrevistas foram individuais e realizadas no próprio local de trabalho, na maioria das vezes nos consultórios ou na biblioteca da instituição, apresentando duração média de aproximadamente uma hora. O procedimento para realização da entrevista abarcava a garantia do anonimato do participante e uma explicação sobre a proposta da pesquisa. Após a assinatura de um termo de consentimento pelo participante, iniciava-se a conversação com um roteiro básico, contendo as questões expostas acima, mas aberto a alterações em função do desenrolar da entrevista. Todas as entrevistas foram gravadas com a devida anuência dos participantes.

\section{Análise dos dados}

A análise foi norteada por três grandes eixos interligados. O primeiro visou compreender como os entrevistados representam seu papel profissional no serviço em questão. O segundo eixo explorou as vivências associadas aos resultados do trabalho, analisando similarmente a ligação dessas vivências com o cumprimento ou não dos diferentes elementos do papel profissional. Por fim, o terceiro eixo abordou as expectativas enquanto futuro profissional e sua possível relação com tais vivências. Unindo-se a outros trabalhos realizados no campo da saúde pública, como os de Azevedo, Fernandes e Carreteiro (2007) e Sá, Carreteiro e Fernandes (2008), a análise do material empírico baseou-se na abordagem da psicossociologia francesa.

\section{RESULTADOS}

O primeiro eixo de análise do material empírico buscou compreender como os entrevistados representam seu papel profissional. Nesse particular, seis deles apontaram determinadas funções no cuidado diretamente dispensado aos usuários do CAPS. Deste modo, o profissional A aponta que seu papel de técnico na assistência à loucura é o de prover "um acolhimento, uma compreensão dos problemas enfrentados pelos pacientes, para que o paciente não se sinta sozinho ao enfrentar os problemas" (Profissional A). Por sua vez, outro entrevistado atesta: "A partir do momento em que me deparei com uma realidade tão crua, acho que nosso papel é tentar diminuir o sofrimento, e é o que as pessoas aqui tentam fazer. Nosso papel é esse” (Profissional B). É possível destacar ainda a fala do profissional $\mathrm{C}$, que afirma: “As possibilidades na assistência são de dar um suporte às pessoas que sofrem tanto. (...) A gente está aqui para ajudá-las a atravessar as crises $e$ 
tentar minimizar os efeitos dos sintomas do sofrimento psíquico" (Profissional C).

Estes trechos trazem à tona representações do papel profissional ancoradas em dois componentes principais: minorar o sofrimento e fornecer acolhimento. A força desses elementos como definidores do papel profissional parece se relacionar com um aspecto muito mencionado nas entrevistas, qual seja, a fragilidade/vulnerabilidade social e familiar geralmente compreendida nos casos. $\mathrm{O}$ contato com esse cenário adverso mobiliza os profissionais afetivamente, movendo-os para o ato assistencial:

"Eu me deparei com uma realidade muito grave, porque, além de psicóticos, a gravidade social é muito alta. E isso tocou em mim. Falei: "puxa, tenho que fazer alguma coisa para além e poder de alguma forma ajudar nessa coisa social" (Profissional B).

A menção à "coisa social" reflete, no fundo, a preocupação com outro elemento do papel profissional. Citada em duas entrevistas, essa temática inclui no papel profissional ações que ultrapassam a questão clínica e do sofrimento psíquico em sua conotação mais estrita e almejam transfigurar a forma como a loucura se encontra inserida na sociedade. Em relevo, desponta a necessidade de uma atuação que consiga lidar com questões familiares, a geração de renda e vínculo com o território, assim como com a luta contra o preconceito sofrido pelos assistidos:

"Faz parte do nosso trabalho essa discussão
política, diferente do ambulatório, que está
preocupado só com a clínica stricto sensu.
No CAPS você está sempre olhando em volta,
e eu quero muito que o preconceito diminua.
A gente vai fazendo o trabalho de
formiguinha para mudar a concepção de
loucura que as pessoas têm lá fora"
(Profissional C).

O segundo eixo de análise averiguou de que maneira os profissionais vivenciavam os resultados da assistência e os eventuais elos dessas vivências com as representações do papel profissional. Como mostram os trechos a seguir, resultados como estabilização e reinserção social dos usuários, além da capacidade de evitar internação, emergem positivados no discurso dos entrevistados e vinculados a uma vivência de realização. Por exemplo, o profissional E coloca:

"A realização decorre destas pequenas coisas. Às vezes o paciente não melhora totalmente, mas consegue se estabilizar. É isso que faz valer à pena. Apesar de tudo ser muito duro, acho que o trabalho tem um retorno imenso" (Profissional E).

Os profissionais F e D afirmam, respectivamente:

\begin{abstract}
"Realização é ver um paciente que quando eu comecei a atender não saía de casa, se autoagredia, estava com o braço todo mordido, não tinha nenhum tipo de atividade, $e$ encontrá-lo bem hoje, fazendo oficinas $e$, fora do CAPS, participando de atividades de mosaico" (Profissional F)
\end{abstract}

\begin{abstract}
"Sinto-me realizado quando através da intervenção a gente consegue realmente dar uma direção para o problema e resolver sem levar para o hospital, internar. Fico feliz da vida quando evito uma internação $e$ o paciente sai daqui saltitante. É uma maravilha!" (Profissional D).
\end{abstract}

Esses relatos sugerem a ligação entre o cumprimento do papel profissional e a vivência de realização, como mostram as duas primeiras falas, nas quais a estabilização e o fim da autoagressão traduzem alívio no sofrimento psíquico. Adicionalmente, a reinserção social do usuário do serviço, aludida na segunda fala quando se menciona atividades fora do CAPS, toca na questão loucura-sociedade, ponto que foi abordado também no papel profissional. Não obstante, o acolhimento (recepção/escuta no momento de entrada no serviço) em si, apesar de ser uma categoria presente no papel profissional, não foi mencionado como elemento atrelado à vivência de realização.

É possível frisar também a autorrealização a partir de uma intervenção capaz de evitar a internação de um usuário. Essa intervenção, malgrado não ter sido mencionada explicitamente no papel profissional, coaduna-se com as políticas públicas que buscam diminuir a hospitalização e a frequência das internações dos usuários. Em adição, as entrevistas sugerem que avanços no atendimento de casos difíceis ensejam, em particular, alto retorno emocional, como demonstra a fala abaixo:

"O caso era uma senhora que estava em crise aguda. Fiz muitas visitas na casa dela, ela me xingava e sofri hostilidade da vizinhança. Agora, depois dos atendimentos, ela está em uma condição melhor, o apartamento está sendo reformado e ela me disse assim: 'Você acredita em mim, né?' $E$ eu disse: 'Claro que sim.' E ela riu e disse: 'Puxa, você é insistente para caramba, né?' Fiquei muito feliz, muito emocionada" (Profissional G). 
Neste relato, cabe realçar o processo de superação das dificuldades na condução do atendimento e, concomitantemente, o fato de as palavras da pessoa assistida sinalizarem o estabelecimento de um vínculo terapêutico positivo e funcionarem como reconhecimento do empenho do técnico. Ambos os elementos parecem impulsionar os afetos positivos acerca dos resultados do trabalho, como expressa o trecho final do relato.

De outra parte, o resultado negativo aparece nas entrevistas, na maioria das vezes, na forma de abandono do serviço por parte dos usuários ou na constatação de que assistência prestada não melhorou seu sofrimento (o que se constitui como não cumprimento de um elemento do papel profissional), desencadeando vivências de frustração e tristeza. Em um dos relatos se lê: "As frustrações ocorrem quando você não consegue dar conta. Às vezes acontece de uma equipe não dar conta de um paciente, de você insistir, insistir e até esperar que ele fique aqui e ele acaba indo embora" (Profissional A). Outro profissional revela: "As maiores frustrações estão na melhora ou na piora dos pacientes. O que me move é diminuir o sofrimento do ser humano" (Profissional B).

Acerca do mesmo tópico, o profissional D afirma: "A frustração ocorre por não poder fazer mais. Me sinto limitada naquilo que eu não posso fazer, me sinto triste, me sinto mal" (Profissional D). Um ponto a ser realçado nessa última fala é como a frustração surge associada à percepção de certos limites às práticas assistenciais, elemento discursivo que emerge nas palavras de outro profissional:

\footnotetext{
"Os limites para uma boa assistência são vários: recursos materiais, humanos, políticos, e acho que a própria gravidade dos casos se impõe como um grande limite, porque parece tudo fácil e não é nem um pouco. Se tivesse tudo em pleno funcionamento, ainda assim seria muito difícil, porque os casos são muito difíceis. A gente sofre muito e consegue pouco" (Profissional C).
}

Ao tratar dos limites, o profissional $\mathrm{C}$ alude primeiro à insuficiência material, de recursos humanos e de sustentação política, problemas referentes à gestão da rede de atenção; contudo o trecho acima aponta que os limites não se restringem a essa esfera maior, pois a complexidade e gravidade da maioria dos casos trazem consigo muitas dificuldades. Assim, na visão do profissional, nem mesmo melhorias administrativas garantiriam êxito na assistência, o que é indício de sua irredutibilidade diante dos problemas de gestão.
Tal gravidade/complexidade, aparentemente, não decorre apenas das desfavoráveis circunstâncias sociais e familiares, visto que nas entrevistas esta surgia fortemente associada a outros dois pontos: a dificuldade de compreender/intervir na loucura e a imprevisibilidade da assistência. Diversos entrevistados fizeram referência a esses pontos e à sua ligação com vivências negativas. Por exemplo, o profissional A expõe: "Você sabe que pacientes com transtornos, bem, uma hora eles estão bem, outra hora eles não estão. É muito difícil para a gente quando eles não estão bem. Sabe, eles podem estar bem hoje, mas amanhã (...) Eles oscilam muito" (Profissional A). Por seu turno, os profissionais $\mathrm{H} \mathrm{e} \mathrm{G}$ afirmam, respectivamente:

\begin{abstract}
"Quando certas situações de atendimento se interrompem é muito frustrante. Então você tem várias conquistas, que acabam se interrompendo com uma nova crise, com a perda do usuário. Você diz: "Meu Deus, estava indo tão bem...' e então você se frustra" (Profissional $\mathrm{H}$ ).
\end{abstract}

"Tem alguma coisa nisso aí que a gente
chama de loucura e que é estranho para todo
o mundo, por mais que a gente se mate de
estudar, de querer entender. Isso que é
estranho, que escapa, traz para a gente uma
angústia e uma impotência absurda em
alguns momentos" (Profissional G).

Diante de quadros clínicos de difícil definição e cuidado, a realização do trabalho em saúde mental depara-se com a obscuridade do desconhecido e do não saber, o que acaba gerando vivências de angústia e impotência. Paradoxalmente, se as dificuldades parecem levar à frustração, visto que diminuem as possibilidades de ação, elas podem também despertar nos profissionais uma posição sóbria com relação aos resultados do trabalho e, inversamente, moderar a frustração, como atestam os profissionais $\mathrm{F} \mathrm{e} \mathrm{C}$ :

\footnotetext{
"Cheguei com muito entusiasmo, com uma ilusão de que funcionava de uma maneira diferente, com resultados mais fáceis. Após as primeiras semanas veio uma sensação de decepção e desânimo. Depois eu voltei a trabalhar com entusiasmo, mas não tão grande quanto no início. Hoje em dia, trabalho de uma maneira tranquila, um trabalho bom na medida do possivel" (Profissional F).

"Imagine um grande show de música, com centenas de milhares de pessoas e um grupo de cinquenta pessoas que quer se encontrar. Alguns conseguem se encontrar no grupo $e$
} 
outros não, porque está todo mundo perdido. A imagem de um show reflete muito o trabalho que a gente faz aqui. Em última instância, sei que vai acabar o show e haverá pessoas que a gente não vai encontrar" (Profissional C).

Baseada nas dificuldades de obter resultados, a primeira citação enquadra o trabalho em certos limites, ao afirmar que ele é "bom na medida do possivel". Além disso, a fala sinaliza que após certo tempo ocorreu o resgate parcial de sua mobilização subjetiva e certa melhora na relação com o trabalho, o que possivelmente decorreu de um processo de elaboração das dificuldades iniciais. $O$ segundo trecho traz a lume, metaforicamente, uma representação do trabalho menos ambiciosa quanto à obtenção de resultados positivos para todos os casos, o que expressa também limites na assistência. A representação dos resultados do trabalho por meio desses limites parece operar no sentido de atenuar os insucessos na assistência.

Não obstante, nem todos os profissionais interiorizaram esse mecanismo. Na entrevista de outro profissional parece se instalar um conflito entre $o$ reconhecimento das dificuldades/limites e a responsabilização pelo êxito assistencial:

\footnotetext{
"Fico muito bem quando vejo que o paciente está melhorando com as minhas intervenções e muito mal quando eu tento, tento, tento $e$ não há melhora nenhuma. Infelizmente, porque quero desconstruir isso, porque sei que não depende só de mim" (Profissional B).
}

Neste caso, por um lado, há uma experiência emocional fortemente vinculada à atuação do profissional na obtenção de resultados nos atendimentos; por outro, existe a crença de que ele não pode se responsabilizar inteiramente pelos resultados da assistência. Provavelmente, mesmo cognitivamente, considerando-se as dificuldades e os limites da assistência ("não depende só de mim"), a interiorização e a elaboração psíquica desses últimos não estão estruturadas o bastante para atenuar a intensidade da frustração, processo que parece ter ocorrido nos outros profissionais citados anteriormente.

O terceiro eixo de análise debruçou-se sobre a relação entre as vivências diante do trabalho e as expectativas de futuro profissional, incluindo sua intenção de continuar ou não trabalhando em serviços como os CAPSs. Com efeito, houve perfeito equilíbrio entre o número de profissionais que tencionavam continuar atuando em CAPSs e aqueles que desejavam outras trajetórias de carreira. Com o intuito de explicitar não somente o conteúdo desse terceiro eixo de análise, mas também sua relação com as vivências sobre os resultados do trabalho, será apresentada a seguir a forma pela qual os profissionais $\mathrm{B}, \mathrm{C}$ e $\mathrm{F}$ (citados em trechos acima) delineiam seu futuro profissional. $\mathrm{O}$ profissional $\mathrm{B}$, mais jovem e com menos tempo de serviço, é o que expressou, na última citação, uma limitada elaboração das dificuldades e limites enquanto mecanismo psíquico atenuador da frustração. Ele, na continuação de sua entrevista, afirma:

\begin{abstract}
"Sinceramente, não estarei em um CAPS. Manter-se em um trabalho como esse é muito desgastante. Existe um cansaço de o tempo inteiro você estar lidando com um nível de estresse muito alto, os pacientes sempre muito graves, difícil de estabilizar e você tendo sempre que ver se o paciente não está legal. Pretendo ter um consultório e atender em ambulatório" (Profissional B).
\end{abstract}

Com mais tempo de serviço, os profissionais $\mathrm{F}$ e C, cujas falas transcritas anteriormente se caracterizaram por uma posição de sobriedade acerca dos resultados do trabalho e de suas frustrações, expressaram-se de modo oposto. Afirma a profissional F: "Embora tenha ficado muitos anos afastada da saúde mental, sempre tive o desejo de permanecer, $e$ acho que vou permanecer sim em CAPS, até que outro desejo maior se instale" (Profissional F).

Por sua vez, o profissional $\mathrm{C}$ explicita:

\begin{abstract}
"Eu não me vejo sem trabalhar em CAPS não. Não faço plano concreto de sair daqui. Uma coisa fora da assistência seria a carreira acadêmica, embora eu não saiba até que ponto estou disposto a correr atrás disso. Por incrivel que pareça, porque é muito difícil de mensurar, me atrai na saúde mental a possibilidade de ver a diferença que o trabalho faz na vida das pessoas" (Profissional C).
\end{abstract}

Nos relatos acima, o profissional B, com o mecanismo de mitigação da frustração menos estruturado, mostrou-se mais inclinado a sair do atendimento em CAPSs, enquanto os outros dois acima apontaram um futuro profissional vinculado à sua atual inserção profissional. O profissional B cita a gravidade dos casos e as dificuldades em entender os indivíduos atendidos por ele como elementos relacionados à sua intenção de saída, elementos esses que parecem trazer consigo uma carga significativa de frustração e afetos negativos quanto aos resultados do trabalho. No caso do profissional $\mathrm{C}$, embora tenha apresentado uma posição sóbria quanto aos resultados 
do trabalho anteriormente, este último trecho revela o efeito dos resultados positivos (quando estes ocorrem) no vínculo do profissional com o trabalho, favorecendo sua permanência nesse tipo de serviço.

\section{DISCUSSÃO}

Em meio à consolidação da reforma psiquiátrica, os profissionais do CAPS estudado delineiam seu papel profissional a partir de determinadas funções psicossociais, tais como acolher os usuários do serviço, atenuar seu sofrimento e alterar a relação entre a sociedade e a loucura. Essas funções figuraram realmente como sentidos para o trabalho dentro de uma leitura clínica (Lévy, 2001), uma vez que conferem significações para o trabalho e mobilizam os profissionais; porém tais funções têm pesos distintos nas representações dos profissionais sobre seu trabalho, sendo mais presentes o acolhimento e a mitigação do sofrimento (próprios ao trabalho clínico) e mais escassas as menções acerca da atuação na relação entre a sociedade e a loucura.

Nos resultados, a menção ao processo de cura não foi explicitada, apesar de ainda estar presente nos serviços de saúde mental, como mostra a revisão de Prebianchi e Falleiros (2011). De outra parte, à semelhança dos resultados de Figueiredo e Rodrigues (2004), aspectos clínicos surgiram de forma mais incisiva do que elementos ligados à reinserção social e à mudança do lugar da loucura na sociedade no papel profissional. Uma possível explicação para a menor presença da atuação na relação sociedade vs loucura talvez resida na adoção de uma estratégia defensiva por parte dos profissionais. Como indicam os resultados da pesquisa, a frustração parece emergir, em geral, do não cumprimento do papel profissional. Se incorporasse plenamente a atuação na relação entre a sociedade e a loucura no papel profissional, o trabalhador assumiria tarefa de grande complexidade e difícil realização, logo, com grande potencial de frustração. Assim, evitando a incorporação dessa função, ele evitaria também possíveis frustrações.

A análise dos relatos aponta que os elementos constituintes do papel profissional apresentam potenciais diferentes para gerar vivências de realização/frustração, como no caso do acolhimento, função que não despontou como fonte explícita de realização. Talvez o acolhimento seja compreendido pelos entrevistados como um dispositivo vinculado a uma etapa do trabalho (a recepção), não figurando, desta forma, como um fim em si mesmo, o que dificultaria a vivência de realização. Como informam Takemoto e Silva (2007), o acolhimento também pode ser compreendido por meio de uma postura contínua diante do usuário, não estando assim restrito a um único momento. Dentro da leitura psicossociológica, este último sentido do acolhimento sublinha sua função estruturante na assistência, isto é, como ponto de sustentação para todo o processo de cuidado, sentido este que talvez possibilitasse maior efetividade no trabalho e propiciasse mais facilmente vivências de realização.

Cabe registrar, ademais, a capacidade de evitar uma internação como um resultado do trabalho que desperta vivências significativas, mesmo não sendo citada, per se, como uma função do papel profissional. Neste caso, as vivências positivas podem advir da consumação de uma ação em linha com uma das bandeiras da reforma psiquiátrica (redução das internações), espelhando assim um processo de identificação diante de seu imaginário e de suas propostas.

De todo modo, conforme advogado por Enriquez (1997), os resultados do trabalho, sejam eles percebidos pelos indivíduos assistidos ou pelos próprios profissionais, revelaram sua relevância no vínculo subjetivo com o trabalho, desencadeando realização, frustração e reações afetivas variadas. A emoção relatada pelo profissional $\mathrm{G}$ no momento em que a usuária do CAPS ressalta seu empenho ilustra a força do reconhecimento, especialmente enquanto elemento capaz de responder aos desejos do profissional (Enriquez, 1994) que, neste caso, buscava prover um cuidado que fizesse diferença na vida da pessoa assistida.

Nas vivências negativas dos resultados do trabalho, os profissionais enfatizaram dificuldades inerentes tanto à gestão do SUS e às condições gerais de trabalho quanto à complexidade de lidar com a loucura e à imprevisibilidade/não saber que a acompanham. Este último ponto converge com o caráter indeterminado da definição de loucura/doença mental detectado por outros pesquisadores (Prebianchi \& Falleiros, 2011). Neste sentido, maior compreensão teórico-clínica da loucura pode ajudar no manejo das vivências relativas aos resultados do trabalho pelos profissionais.

Especialmente no que toca às dificuldades de lidar com a loucura, em um primeiro momento é possível esperar que essas despertem frustração, porquanto diminuem o controle do processo de trabalho; contudo tais dificuldades foram reapropriadas por alguns profissionais da amostra como algo próprio ao trabalho de cuidar da clientela dos CAPSs, limites intrínsecos que precisam ser sustentados intersubjetivamente pela equipe técnica. A incorporação desses limites intrínsecos à representação do trabalho por parte dos profissionais pode cumprir a função psíquica de relativizar as 
frustrações e os afetos negativos diante dos resultados da assistência. Ao conceber o trabalho pelos seus limites, fica exemplificado o constante trabalho representacional dos indivíduos na significação do seu trabalho (Lévy, 2001).

Não obstante, tal mecanismo não opera da mesma forma para todos os indivíduos. O caso do profissional $\mathrm{B}$ (mais jovem e com menos tempo de serviço) parece emblemático neste sentido. Mesmo considerando a influência de fatores externos à sua atuação, as falas desse profissional sugerem que os resultados negativos na assistência (o fato de o usuário do serviço não melhorar) lograram ferir seus apelos narcísicos, desencadeando vivências negativas. Suas frustrações não estão moderadas a contento nem incorporadas como algo inerente ao trabalho, ao contrário dos experientes profissionais C e F. Tal situação, que, levada ao extremo, fragiliza o futuro do entrevistado nesse tipo de serviço, retrata a necessidade de o profissional lidar com sua própria insuficiência perante os desafios/ideais do novo modelo assistencial e coloca em xeque as possibilidades de reconhecimento social vinculadas ao contrato narcísico (Kaës, 1997), que supõe nos profissionais a capacidade de intervir efetivamente na vida dos usuários.

Os relatos dos profissionais B, C e F coadunam-se com a pesquisa de Rebouças, Legay e Abelha (2007), que, mesmo partindo de outro referencial de análise, diferenciam profissionais mais experientes e menos experientes na relação afetiva com o trabalho e no papel das estratégias de adaptação. No fundo, a reapropriação das dificuldades como limites intrínsecos mencionada acima parece ilustrar uma dessas estratégias, que se encontra mais consolidada em profissionais com maior experiência, permitindo um elo menos desgastante com o trabalho e favorecendo sua permanência em serviços como os CAPSs.

Parece correto supor a existência de outros fatores capazes de influenciar as expectativas de futuro dos profissionais além das vivências diante dos resultados do trabalho, como, por exemplo, eventuais dificuldades de realocação profissional em outros campos. Por outro lado, os presentes resultados trazem a lume indícios de que, nessa temática, não se pode desprezar o papel da realização e da frustração, tampouco o papel dos mecanismos psíquicos que modulam a emergência de tais vivências.

\section{CONSIDERAÇÕES FINAIS}

Em rigor, todas as inserções profissionais são potencialmente capazes de ensejar nos trabalhadores experiências/reações afetivas associadas às suas respectivas avaliações dos resultados do trabalho, podendo precipitar, também, mecanismos psíquicos que interferem na relação dos sujeitos com tais resultados. Na saúde mental, destaca-se a percepção de certos limites intrínsecos (complexidade e imprevisibilidade da loucura) no que toca às vivências de frustração e sua elaboração. As percepções relativas a esses limites intrínsecos talvez estejam ancoradas, pelo menos parcialmente, na dificuldade da loucura em se encaixar no modelo assistencial de outras áreas da saúde, nas quais as rotinas e os protocolos de tratamento se fazem mais presentes e os desacordos teórico-conceituais parecem menos profundos. Como a assistência à loucura escapa desse padrão, a percepção de controle sobre o processo se reduz e surgem então os relatos sobre a imprevisibilidade e complexidade do cuidado.

De toda forma, os profissionais da saúde mental, ao se lançarem no desafio da assistência, operam em um campo multifacetado e com baixo nível de padronização, no qual o espaço relacional assume inconteste relevância. Neste contexto, as formas de vivenciar os resultados do cuidado e o próprio contato com os usuários do serviço encontrados nessa pesquisa sugerem uma relação com o trabalho rica em experiências afetivas, mesmo que existam mecanismos capazes de moderar vivências negativas.

Por fim, cumpre destacar que, entre os limites da pesquisa, estão a ausência do ponto de vista de outros atores na assistência (usuários, familiares e gestores) e a menor ênfase dada às condições materiais e institucionais de trabalho bem como à influência da equipe e da liderança nos temas estudados. Não obstante, ao enfatizar outros elementos, a expectativa é que o recorte aqui adotado contribua para aprofundar o conhecimento sobre os mecanismos subjacentes ao vínculo subjetivo entre o profissional e o trabalho na saúde mental. Pesquisas futuras decerto ajudarão a promover reflexão nos profissionais e gestores da área, bem como a auxiliar na formulação de dispositivos institucionais que induzam uma ligação afetiva favorável dos profissionais com seu trabalho; e provavelmente, tais iniciativas apresentarão efeitos positivos no atendimento oferecido aos indivíduos assistidos nesses serviços.

\section{REFERÊNCIAS}

Araújo, J. N. G. (2002). [Resenha do livro Ciências clínicas e organizações sociais de A. Lévy]. Psicologia em Revista, 8, 133-135.

Azevedo, C. S., Fernandes, M. I. A., \& Carreteiro, T. C. (2007). Sob o domínio da urgência: a prática de 
diretores de hospitais públicos do Rio de Janeiro, Brasil. Cadernos de Saúde Pública, 23, 2410-2420.

Bertaux, D. (1997). Lesrécits de vie. Paris: Éditions Nathan.

Bezerra Júnior, B. (1999). A diversidade no campo psiquiátrico: pluralidade ou fragmentação. Cadernos IPUB, 14,135-144.

Blankertz, L. E., \& Robinson, S. E. (1997). Turnover intentions ofcommunity mental health workers in psychosocialrehabilitation services. Community Mental Health Journal, 33,517-529.

Brasil. Ministério da Saúde (2004). Saúde mental no SUS: os centros de atenção psicossocial. Brasília: Ministério da Saúde.

Bueno, M. L., \& Caponi, S. (2009). A construção do discurso dos sujeitos envolvidos com o processo de reforma psiquiátrica: um estudo sobre o município de Joinville/SC. Interface (Botucatu), 13, 137-150.

Enriquez, E. (1994). O papel do sujeito humano na dinâmica social. In A. Lévy (Org.). Psicossociologia: Análise social e intervenção (pp. 25-49). Petrópolis, RJ: Vozes.

Enriquez, E. (1997). A Organização em Análise. Petrópolis, RJ: Vozes.

Figueiredo. V. V., \& Rodrigues, M. M. P. (2004). Atuação do psicólogo nos CAPS do estado do Espírito Santo. Psicologia em Estudo, 9, 173-181.

Freitas, M. E. (2000). A Questão do Imaginário e a Fronteira entre a Cultura da Organização e a Psicanálise. In M.E. Freitas, \& F. C. Prestes Motta (Orgs.). Vida Psíquica e Organização (pp. 41-73). Rio de Janeiro: FGV.

Garcia, M. L. P., \& Jorge, M. S. B. (2006). Vivência de trabalhadores de um centro de atenção psicossocial: estudo à luz do pensamento de Martin Heidegger e Hans-Georg.Ciência \& Saúde Coletiva,11, 765-774.

Honorato, C., \& Pinheiro, R. (2008). O trabalho do profissional de saúde mental em um processo de desinstitucionalização. Physis, 18, 361-380.

Käes, R. (1997). O grupo e o sujeito do grupo: elementos para uma teoria psicanalítica do grupo. São Paulo: Casa do Psicólogo.

Koda, M. Y., \& Fernandes, M. I. (2007). A reforma psiquiátrica e a constituição de práticas substitutivas em saúde mental: uma leitura institucional sobre a experiência de um núcleo de atenção psicossocial. Cadernos de Saúde Pública, 23, 1455-1461.
Lévy, A (2001). Ciências clínicas e organizações sociais. Belo Horizonte: Autêntica.

Nunes, M., Torrenté, M., Ottoni, V., Moraes Neto, V., \& Santana, M. (2008). A dinâmica do cuidado em saúde mental: signos, significados e práticas de profissionais em um Centro de Assistência Psicossocial em Salvador, Bahia, Brasil. Cadernos de Saúde Pública, 24, 188-196.

Pinto, A. T, \& Ferreira, A. A. (2010). Problematizando a reforma psiquiátrica brasileira: a genealogia da reabilitação psicossocial. Psicologia em Estudo, 15, 27-34.

Prebianchi, H. B., \& Falleiros, G. G. (2011). Doença mental: representações de usuários e de profissionais da saúde. Psicologia em Estudo, 16, 33-41.

Rebouças, D., Legay, L., \& Abelha, L. (2007). Satisfação com o trabalhoe impacto causado nos profissionais de serviço de saúde mental. Revista de Saúde Pública, 41, 244-250.

Sá, M. C. (2009). A fraternidade em questão: um olhar psicossociológico sobre o cuidado e a "humanização" das práticas de saúde. Interface (Botucatu), 13, 651666.

Sá, M. C., Carreteiro, T. C., \& Fernandes, M. I. A. (2008). Limites do cuidado: representações e processos inconscientes sobre a população na porta de entrada de um hospital de emergência. Cadernos de Saúde Pública, 24, 1334-1343.

Takemoto, M. L., \& Silva, E. M. (2007). Acolhimento e transformações no processo de trabalho de enfermagem em unidades básicas de saúde de Campinas, São Paulo, Brasil. Cadernos de Saúde Pública, 23, 331-340.

Vasconcellos, V. C. (2010). Realização e frustração profissional em um centro de atenção psicossocial: representações e afetos no trabalho em saúde mental. [Resumo]. In Sociedade Brasileira de Psicologia Organizacional e do Trabalho (Org.). Anais do IV Congresso Brasileiro de Psicologia Organizacional e do Trabalho. Recuperado em 06 de novembro de 2011 de http://www.sbpot.org.br/ivcbpot/trabalhos.

Recebido em 07-11-2011 Aceito em 03-08-2012
Endereço para correspondência:
Vinicius Vasconcellos. Avenida João Carlos Machado, 240, ap. 201, CEP 22620082, Rio de Janeiro- RJ, Brasil. E-mail: viniciuscarvalhodevasconcellos@gmail.com. 